\title{
IMPROVEMENT OF THE CARGO FLEET VESSELS POWER PLANTS ECOLOGICAL INDEXES BY DEVELOPMENT OF THE EXHAUST GAS SYSTEMS
}

\author{
Valerii Kuznetsov* \\ Boris Dymo \\ Svitlana Kuznetsova \\ Mykola Bondarenko \\ Admiral Makarov National University of Shipbuilding, Ukraine \\ Andrii Voloshyn \\ State Research Design \& Shipbuilding Centre, Ukraine \\ *Corresponding author: valeriy.kuznetsov@nuos.edu.ua (V.Kuznetsov)
}

\begin{abstract}
Modernisation of the power plants of cargo fleet vessels to satisfy the requirements set out by the International Maritime Organisation is an urgent scientific and technical problem. The article presents the results of developing a solution to this problem that focuses on the exhaust gas system. We propose the use of ejection nozzles as part of this system. It was found that when the ejection coefficient in these nozzles is $n=3$, it is possible to exclude the use of SCR reactors, thus reducing the operating costs of the marine power plant. Using a mathematical modelling method, the efficiency of operation of six types of nozzle as part of the exhaust gas system was investigated, and a constructive layout was proposed for the gas ducts and inlet louvres for supplying ambient air.

To increase the efficiency of the proposed system, we consider several options for intensifying heat transfer processes through the use of dimple systems in the nozzles and nozzles with swirling flow. We found that these technical solutions would make it possible to further increase the efficiency of the systems by up to $19 \%$ abs.
\end{abstract}

Keywords: marine power plant, emissions, gas-air cooler, nozzle, intensification

\section{INTRODUCTION}

The introduction of new requirements by the International Maritime Organisation (IMO) has given rise to a need to improve the existing cargo fleet to ensure the possibility of working under modern conditions.

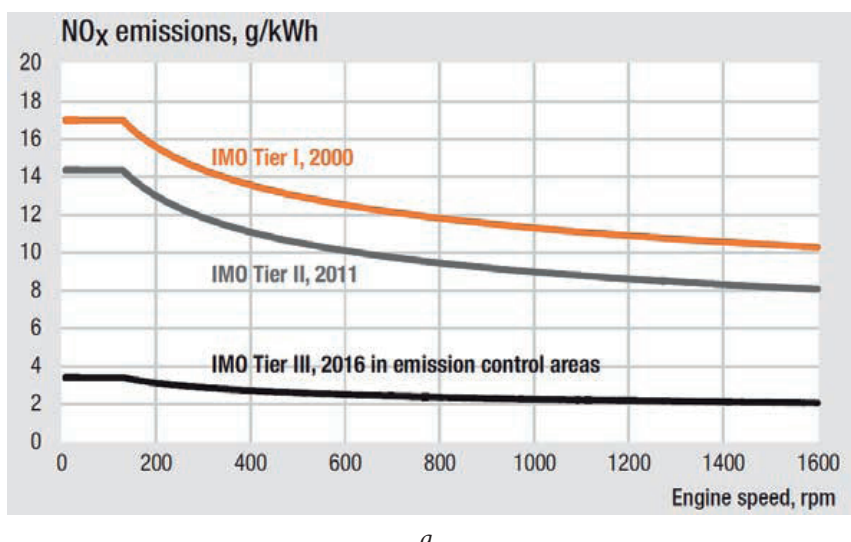

The main focus of these new requirements is a significant reduction in the levels of harmful emissions of $\mathrm{NO}_{x}$ and $\mathrm{SO}_{x}$ (Fig. 1), since these constitute the highest proportion of the exhaust gases from diesel engines $[1,2]$.

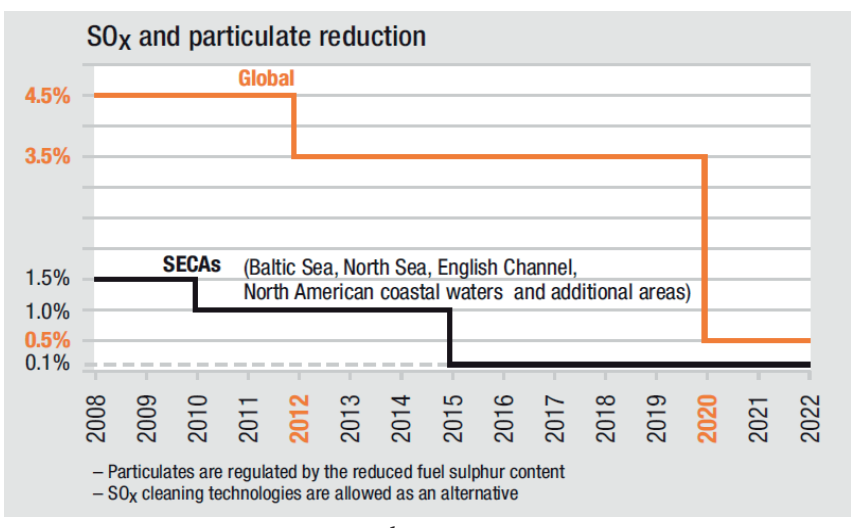

$b$

Fig. 1. Reduction of the levels of harmful emissions in accordance with the requirements of the IMO: $a-N O_{x}$ emissions; $b-S O_{x}$ emissions 
The areas of operation of modern vessels are wide, and include special zones- (the South Sea, the Baltic Sea, the English Channel, etc.), meaning that it is necessary to implement appropriate measures to meet the requirements for emissions of harmful substances. A reduction in $N O_{x}$ emissions can be achieved by reducing the level of sulphur in the fuel, for example by using light fuels. However, the presence of nitrogen in the fuel makes it necessary to reduce the level of $\mathrm{NO}_{x}$ in the exhaust gases. One option for solving this problem is to improve the exhaust gas systems of marine power plants, and the present work addresses this topic.

\section{IDENTIFICATION OF THE INVESTIGATION OBJECT}

Modern methods of reducing the emissions of harmful substances from vessels can be divided into active and passive approaches.

Active methods include those that directly affect the flow of gases, and require the installation of additional equipment in the engine room. These include thermochemical heat recovery systems, scrubber systems, SCR reactors, and the recirculation of exhaust gases from heat engines.

The thermochemical and thermoacoustic use of the heat of exhaust gases from marine power plants can be an effective way to reduce harmful emissions $[3,4,5,6]$. However, these methods require the installation of a significant amount of equipment in the vessel's engine room.

One effective way of improving ecological indices is the use of water-fuel emulsions [7]; however, this method requires the use of a special fuel preparation system. To improve the ecological indices of marine power plants, Wartsila proposed a gas cleaning system (Fig. 2) [8]. To reduce the weight-size parameters of the system, a diffuser system with several inlets can be used (Fig. 3).

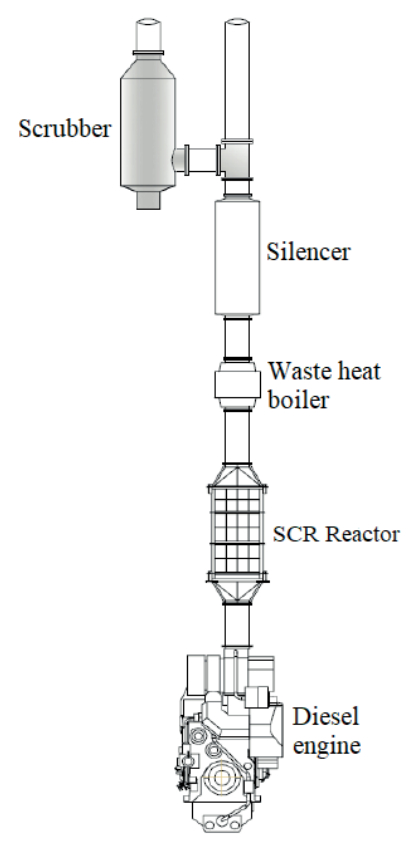

Fig.2 Direct-flow gas cleaning system

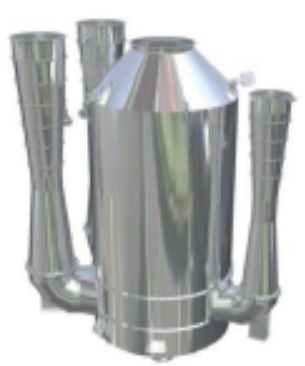

Fig.3. Diffuser system
These systems can operate on open or closed circuits, and can be installed both on newly built vessels and as part of the modernisation of existing marine power plants. One of the most significant elements of such systems are SCR reactors (Fig. 4) [9]. However, the efficiency of this approach does not exceed 95\% [10], and it is therefore advisable to develop other ways of reducing the level of $\mathrm{NO}_{x}$ emissions that can help to improve the efficiency and reduce the weight-size parameters [11-14].

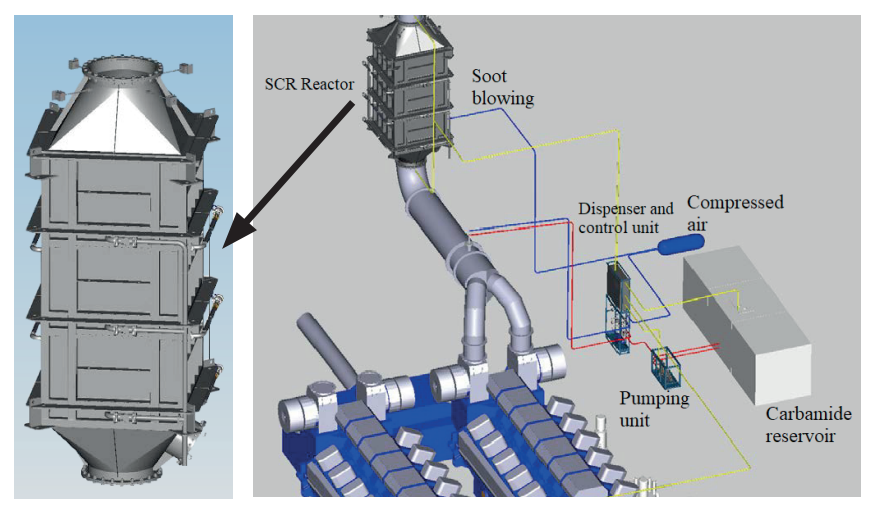

Fig.4 SCR reactor system

Alfa Laval has developed the Pure $S_{x}$ Express system to reduce the $S O_{x}$ level, as shown in Fig. 5 [11].

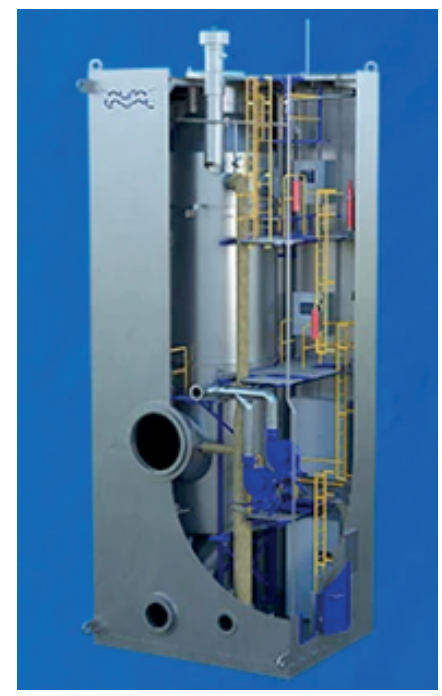

Fig.5 The Pure $\mathrm{SO}_{x}$ Express system from Alfa Laval

This system allows vessels to continue to use heavy fuel oil while still meeting the Tier II and III requirements for $S_{x}$ emissions. However, the use of these scrubber systems necessitates the selection of scrubber elements, depending on the operating mode [15], and also causes problems in terms of the disposal of water from scrubber washing, especially when vessels are at sea [16].

An alternative method of absorbing $\mathrm{SO}_{2}$ and $\mathrm{NO}$ from engine exhaust gases involves the use of $\mathrm{Na}_{2} \mathrm{~S}_{2} \mathrm{O}_{8}$ [17]. Reductions in early injection timing, exhaust gas recirculation, and water injection into the cylinder are other techniques that 
have been considered for reducing the level of $\mathrm{NO}_{x}$ in the exhaust gases of diesel engines [10,11]. A schematic diagram of a gas recirculation system is shown in Fig. 6 .

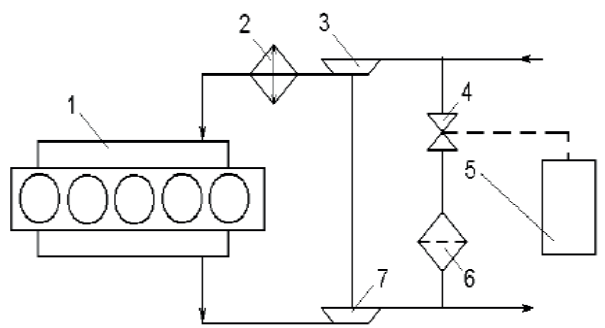

Fig. 6. Schematic diagram of a gas recirculation system: 1 - diesel engine; 2 - cooler; 3 - compressor; 4 -valve; 5 - control unit; 6 - filter; 7 - turbine

The degree of recirculation can be used as an indicator, as follows:

$$
k_{R}=\frac{M_{G}}{M_{G}+M_{A}} \cdot 100 \%
$$

where $M_{G}, M_{A}$ are the masses of bypass gas and air in the engine cylinder.

Gas recirculation slows down the combustion process, which leads to a decrease in the amount of $N O_{x}$ emissions (Fig. 7).

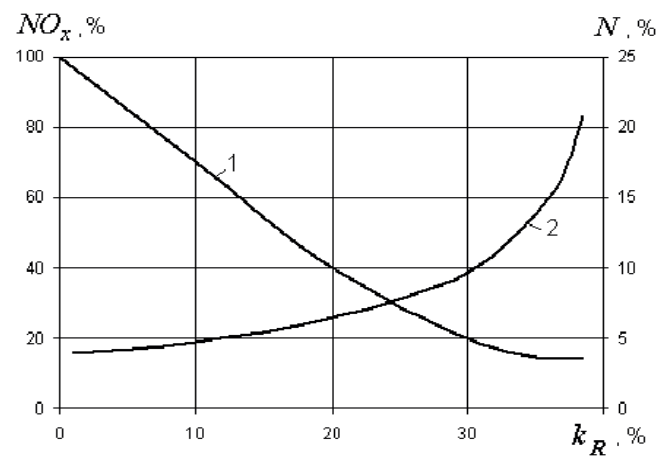

Fig. 7. Reductions in $\mathrm{NO}_{x}(1)$ and smoke (2) emissions versus the degree of recirculation [6]

Although recirculation can reduce the emissions of nitrogen oxides, the soot yield increases and the fuel efficiency of the engine decreases, and this is particularly evident at full loads. For this reason, this approach is economically justified only at partial engine operating modes and at recirculation rates of $12-20 \%[10,11,12]$.

When methods are used to reduce the levels of harmful emissions in the exhaust gases of marine power plants, a significant amount of space is required in the engine room to accommodate the necessary equipment and containers. These methods do not provide complete cleaning of exhaust gases from harmful emissions, and are expensive to operate. The choice of method also depends on the type and mode of operation of the vessel [13], which can significantly limit their application.

One way to solve this problem is to develop additional, passive ways of reducing the level of harmful emissions by upgrading the gas exhaust system. These methods can be used with or without the above active techniques.

\section{EXPERIMENTAL METHOD}

The processes of movement of exhaust gases in power plants systems were investigated using a mathematical modelling method. The motion processes and heat transfer were mathematically modelled by finding numerical solutions to the following equations [18]:

\section{Continuity:}

$$
\frac{\partial \rho}{\partial t}+\nabla(\rho \vec{V})=0
$$

where $\rho$ is the mass flow density, and $\vec{V}$ is the vector of the local fluid velocity;

\section{Momentum:}

$\frac{\partial(\rho \vec{V})}{\partial t}+\nabla(\rho \vec{V} \vec{V})=\nabla p+\nabla \tau+\rho \vec{g}+\vec{F}$

where $p$ is the static pressure, $\rho \vec{g}$ is the gravitational force per unit mass, $\vec{F}$ are the external forces acting on the flow and $\tau$ is the pressure tensor;

\section{Energy conservation:}

$$
\frac{\partial(\rho E)}{\partial t}+\nabla(\vec{V}(\rho E+p))=\nabla\left(-\vec{J}_{q}+\left(\tau_{e f f} \vec{V}\right)\right)
$$

where $\vec{J}_{q}$ is the heat flow density, $E=h-\frac{p}{\rho}+\frac{V^{2}}{2}$ is the total energy of the working fluid, $h$ is the working fluid enthalpy, and the expression $\tau_{\text {eff }} \vec{V}$ represents viscous heating.

The system of equations presented above is not closed; it can be closed by adding semi-empirical equations for the pressure tensor, the heat flux, the equation of state for ideal gases, and the differential equations of the turbulence model.

Newton's law: By neglecting the bulk viscosity, the stress tensor can be represented as

$$
\tau=\mu\left[\nabla \vec{V}+(\nabla \vec{V})^{T}-\frac{2}{3} \nabla(\vec{V} I)\right]
$$

where $\mu$ is the coefficient of molecular viscosity, and $I$ is the unit vector.

Fourier's law: The heat flow is determined by the expression

$$
\vec{J}_{q}=-\lambda_{e f f} \nabla T
$$

where $\lambda_{\text {eff }}=\lambda+\lambda_{t}$ is the coefficient of effective conductivity. 
Mendeleev-Clapeyron's law: The basic law of an ideal gas, which establishes a relationship between the main thermodynamic parameters, takes the form

$$
p=R \cdot \rho \cdot T
$$

where $R$ is the individual gas constant for the working fluid.

On the basis of the recommendations given in $[19,20]$, the RSM turbulence model was used to close the system of equations (1)-(6). To solve the resulting system, the RANS approach was implemented using the Code Saturne software package with a free license [21] and the SimScale cloud service [22].

The mathematical model was verified by comparing the results of numerical modelling with experimental data from a full-scale bench test of a model of a ship's gas-air cooler. The discrepancy between the results did not exceed 5\% [23].

\section{EVALUATION OF EFFICIENCY OF USING A GAS-AIR COOLER TO IMPROVE THE ECOLOGICAL INDEXES OF POWER PLANTS}

Passive methods of reducing the level of harmful substances in emissions are those that can perform their functions both with and without active methods, do not require the installation of significant additional equipment and are integrated into the existing structures of vessels without the need for significant re-design.

An example of such a system is the use of ship ejection air coolers (Fig. 8) [23, 24]. In this approach, the energy of the exhaust gases is used to operate the air cooler. The exhaust gas flow (ejection flow) is actively mixed with the external environmental flow (ejected flow), thus reducing the temperature of the gas-air flow.

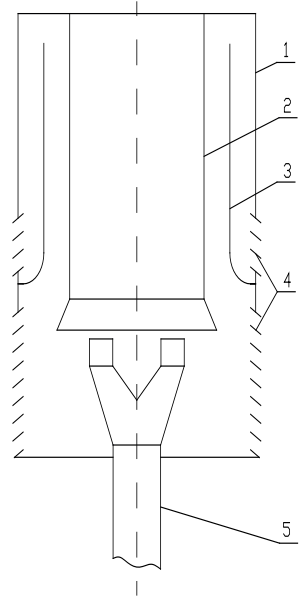

Fig. 8 Exhaust gas system with an ejection-type air cooler: 1 - casing; 2 mixer; 3 - mixer screen; 4 -air inlet louvers; 5 - gas duct with a nozzle.
A reduction in the temperature of the exhaust gases is achieved by intensifying the process of mixing them with the ambient air, shielding a part of the exhaust gases flow and heated pipe elements with surfaces that are cooled. The disadvantages of this constructive solution include the need for a significant amount of cooling of atmospheric air to ensure the required degree of cooling of the exhaust gases, meaning that it is necessary to provide air intake louvres with a large area on the outer walls of the chimney casing. This should not pose a problem, since inlet and exit louvres for natural ventilation of the casing are installed on cargo vessels (Figs. 9 and 10).

Through the modernisation of the internal elements of the casing, ejection nozzles can be installed at the lower level of the inlet louvres, inlet louvres can be provided around the entire perimeter of the casing and a mixing chamber can be installed (Fig. 11).

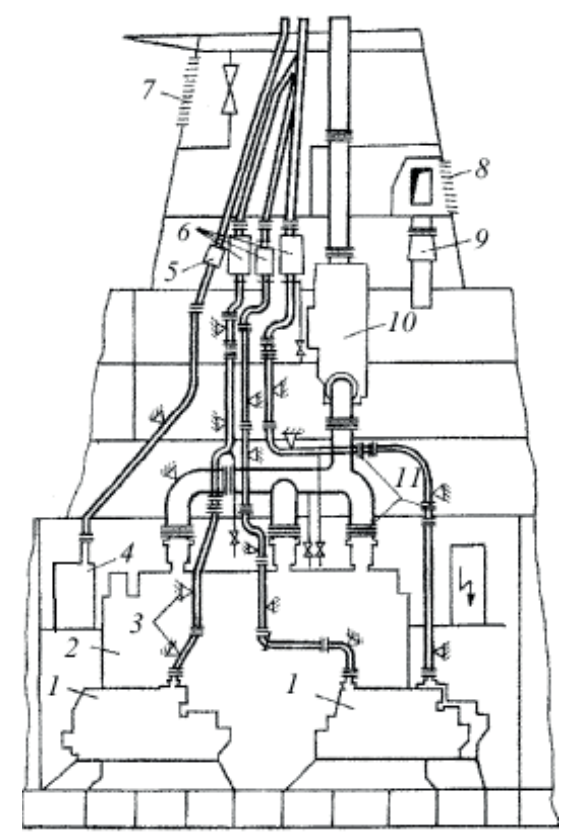

Fig. 9. Diesel plant exhaust gas system: 1 - diesel-driven alternator; 2 - main engine; 3 -support; 4 - auxiliary boiler; 5 -steam spark arrester; 6 - spark arrestor-silencer; 7, 8 - inlet and outlet louvers, respectively, for natural ventilation of the chimney casing; 9 - blower fan; 10 - waste heat boiler; 11 - compensators

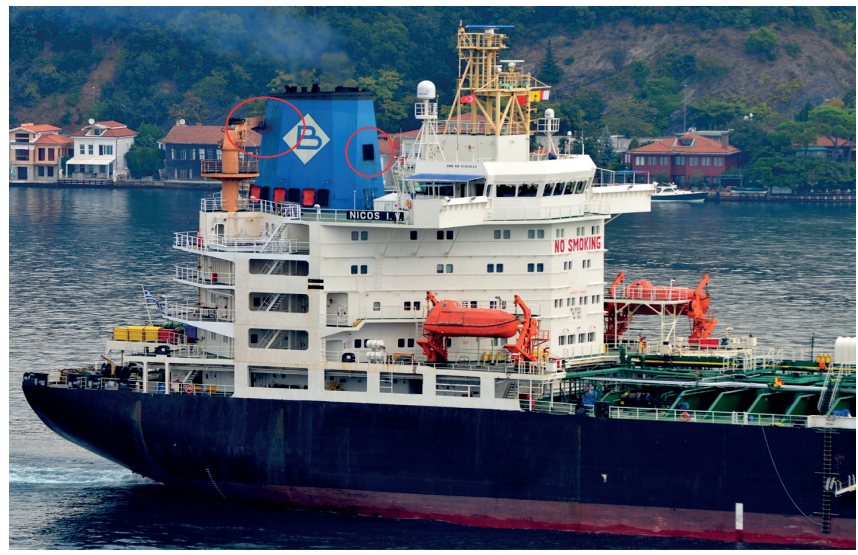

Fig. 10. Superstructure of a tanker with a deadweight of 45,564 $t$ with inlet louvres 


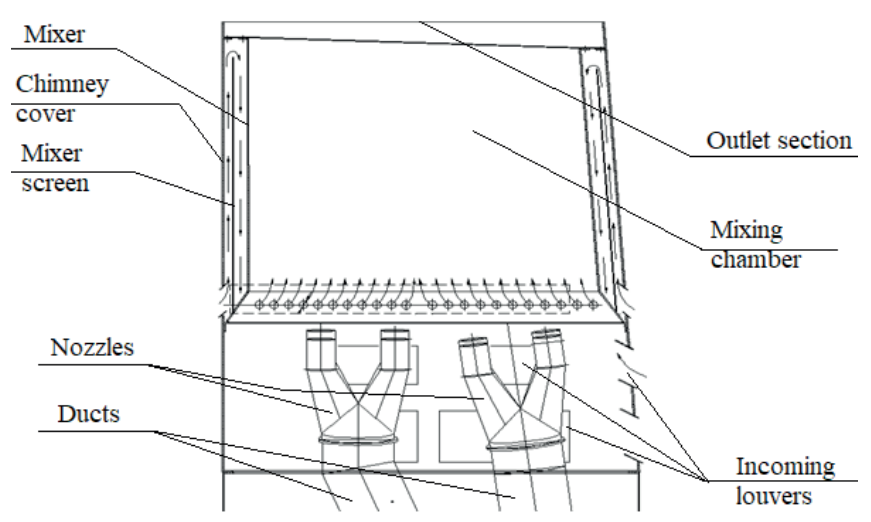

Fig.11 Structural scheme of gas ducts and incoming louvers for supplying environmental air in a gas-air cooler

The concentration of harmful emissions can be represented by a parameter that is inversely proportional to the value of the ejection coefficient $n$ :

\section{$C(\mathrm{~kg}$ emissions / $\mathrm{kg}$ gas mixture $)=C_{\sigma^{\prime}} /(1+n)$}

The ejection coefficient is calculated as set out in [24]:

$$
\mathrm{n}=1,03 \frac{1-\hat{\mathrm{o}}}{\hat{\mathrm{O}}-\Theta}
$$

where 1.03 is an empirical coefficient; $\hat{\mathrm{o}}=\frac{T_{3}}{T_{1}}, T_{1}, T_{3}$ are the temperatures at the inlet and outlet of the air cooler, respectively, in degrees $\mathrm{K}$; and $\Theta=\frac{T_{2}}{T_{1}}, T_{2}$ is the environment temperature, in degrees $\mathrm{K}$.

The drag coefficient of the nozzle is calculated as follows [24]:

$$
\zeta=\frac{\Delta p}{\rho w^{2} / 2}
$$

where $\Delta p$ is the pressure loss in the nozzle, in $\mathrm{Pa} ; \rho$ is the flow density, in $\mathrm{kg} / \mathrm{m}^{3}$; and $w$ is the flow velocity, in $\mathrm{m} / \mathrm{s}$.

The baseline emission level is $C_{N O x}=14 \mathrm{~g} /(\mathrm{kWh})$, which meets the Tier II requirements of the IMO (Fig. 1a). Changes in the emission level in the range $n=1$ to 3 are shown in Fig. 12.

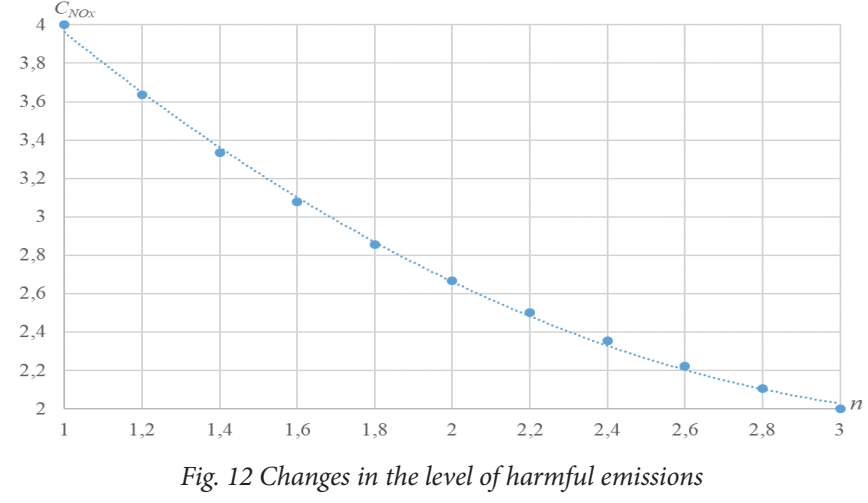

An analysis of this graph shows that when the ejection coefficient in the nozzles is $n=3$, it is possible to meet the Tier III requirements for $\mathrm{NO}_{x}$ emissions without using SCR reactors. However, this is an ideal case, and depends on the composition and operating mode of the power plant; if this scheme cannot fully replace SCR reactors, it may be able to partially replace them.

Various types of nozzles can be used for the practical implementation of ejection cooling. The types of nozzles that can be used in air coolers are shown in Fig. 13 [24].

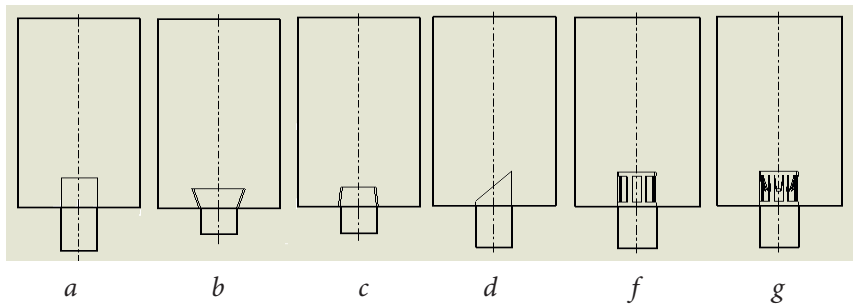

Fig.13 Structures of ejection nozzles: $a$-cylindrical; $b$ - diffuser; $c$-confuser; $d$-oblique cut; $f$ - with longitudinal perforation; $g$ - with perforations and petals

Calculation results for each type of nozzle are shown in Table 1.

Tab. 1. Characteristics of the ejection nozzles investigated here

\begin{tabular}{|l|c|c|}
\hline \multicolumn{1}{|c|}{ Type of ejection nozzle } & Ejection coefficient & Drag coefficient \\
\hline Cylindrical & 1.15 & 0.01 \\
\hline Diffuser & 1.05 & 0.11 \\
\hline Confuser & 1.35 & 0.12 \\
\hline Oblique cut & 2.90 & 0.57 \\
\hline $\begin{array}{l}\text { With longitudinal } \\
\text { perforation }\end{array}$ & 2.40 & 1.30 \\
\hline With perforations and petals & 2.27 & 0.80 \\
\hline
\end{tabular}

The results in Table 1 show that the optimum statistics (the highest ejection coefficient and the lowest drag coefficient) were obtained for the nozzle with an oblique cut, meaning that the use of this tip will give the best results. However, the final choice of nozzle type will be made at the design stage of the system. 
According to equation (8), an increase in the value of the ejection coefficient is possible due to a decrease in the temperature behind the nozzle. One option for implementing this condition involves the intensification of heat transfer processes in the air cooler. There are two possible methods of achieving this: the use of dimple systems, and the use of nozzles with swirling flow. A feature of dimple systems is that the increase in the heat transfer outstrips the increase in the resistance, which is important in gas release systems for vessel engines. The second method can provide better heat transfer, due to better mixing of the streams.

Fig. 14 shows a variant of the diffuser nozzle with dimples located in an area of constant diameter. We investigated options for the locations of holes in areas with constant and variable cross-sections, for diffuser, confuser and oblique cut nozzles. The parameters and the location of the dimples were set based on the recommendations given in [25].

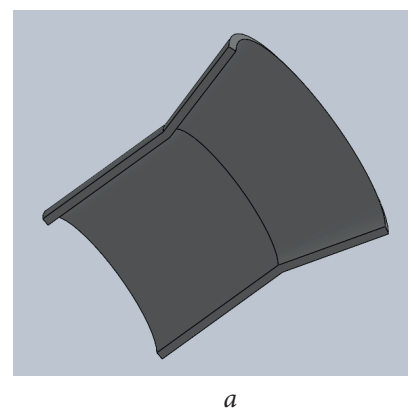

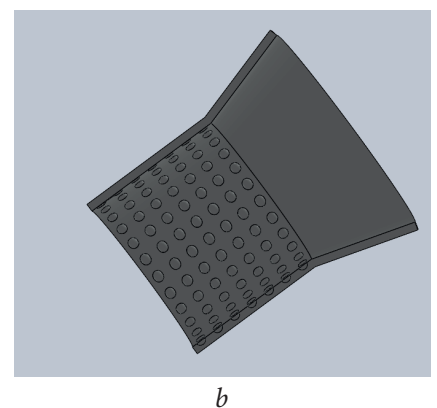

Fig. 14 Arrangement of dimples on a diffuser nozzle: $a$ - basic version; $b$ - variant with dimples

Figure 15 shows a nozzle with swirling flow. The packing parameters (twist angle, cut diameter) were estimated based on the recommendations set out in [26].

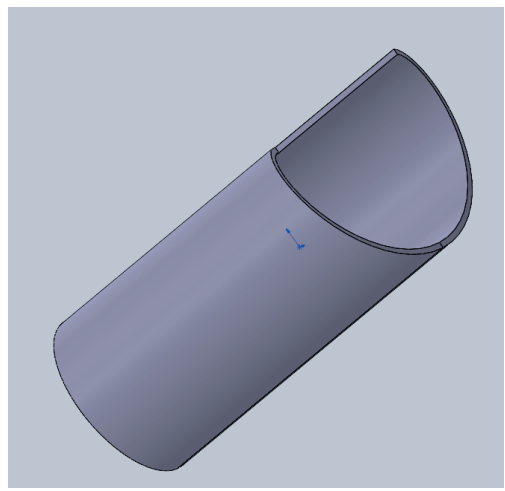

Fig. 15 Nozzle with swirling flow

Calculations were carried out for gas inlet temperatures of $300-450^{\circ} \mathrm{C}$ and Reynolds numbers of $6,000-20,000$. The results showed that an intensification of the heat transfer processes reduces the gas temperature behind the cooler to $17 \%$ abs. when the dimple systems are used, and for swirling flow in smooth channels, this rises to $19 \%$ abs. According to equation (8), this will lead to a similar increase in the ejection coefficient and the entire ejection cooling system. However, this is the maximum value that can be expected, and depends on the composition and operating mode of the power plant.

\section{DISCUSSION OF RESULTS}

The modernisation of marine power plants that are currently in operation to comply with the Tier III requirements of the IMO is an urgent scientific and technical problem. The results obtained here show that the cost of modernisation can be reduced by developing exhaust gas systems. This will ensure compliance with $N O_{x}$ emission regulations.

The proposed design can be used either as a backup for SCR reactors or as an independent system that can significantly reduce the cost of operating a marine power plant. Intensification of heat transfer in the elements of the system can further increase its efficiency by up to $19 \%$ abs.

Further research will focus on optimising the size and locations of the dimples in the attachments, and the design characteristics of the nozzle with swirling flow, to achieve the maximum efficiency of gas exhaust devices depending on the operating mode of the power plant.

\section{CONCLUSIONS}

In this study, we propose the use of ejection cooling devices as part of an exhaust gas system to improve the ecological indices of marine power plants. The use of these devices will reduce the level of $\mathrm{NO}_{x}$ emissions in exhaust gases and the cost of operating marine SCR reactors in exhaust gas systems. It is shown here that implementation of the proposed solution will not lead to significant economic cost as part of the modernisation of an exhaust gas system.

The efficiency of various types of ejection nozzles as components of air coolers was investigated, and the results showed that it is possible to achieve compliance with Tier III IMO standards on $\mathrm{NO}_{x}$ emissions without using SCR reactors, although this depends on the power of the engines and the operating modes of the power plant.

The possibility of intensifying the heat transfer processes in the ejection nozzles is considered in terms of further improvement in ejection coolers. The use of dimple systems and flow swirling in nozzles was found to be effective. The intensification of heat transfer processes in the nozzles made it possible to increase the effects of the system by up to $19 \%$ abs.

\section{REFERENCES}

1. MARPOL 73/78 Dodatok VI (take a look) before the Convention "Rules for the protection of shipwrecking". Retrieved from http://docs.cntd. ua/document/499014496.

2. Z. Yang, Q. Tan, and P. Geng, "Combustion and emissions investigation on low-speed two-stroke marine diesel engine with low sulfur diesel fuel," Polish Maritime Research, 
vol. 1, no. 101, pp. 153-161, 2019. Retrieved from: https:// doi.org/10.2478/pomr-2019-0017.

3. O. Cherednichenko and V. Mitienkova, "Analysis of the impact of thermochemical recuperation of waste heat on the energy efficiency of gas carriers," Journal of Marine Science and Application, 2020. Retrieved from https://doi. org/10.1007/s11804-020-00127-5.

4. O. Cherednichenko, S. Serbin, and M. Dzida, "Application of thermo-chemical technologies for conversion of associated gas in diesel-gas turbine installations for oil and gas floating units," Polish Maritime Research, vol. 26, no. 3, pp. 181-187, 2019. Retrieved from https://doi.org/10.2478/ pomr-2019-0059.

5. Y. Kondratenko, V. Korobko, O. Korobko, G. Kondratenko, and O. Kozlov, "Green-IT approach to design and optimization of thermoacoustic waste heat utilization plant based on soft computing," Studies in Systems, Decision and Control, 287-311, 2017. Retrieved from http://doi.org/ doi:10.1007/978-3-319-55595-9_14.

6. Y. Kondratenko, S. Serbin, V. Korobko, and O. Korobko, "Optimisation of bi-directional pulse turbine for waste heat utilization plant based on green IT paradigm" Studies in Systems, Decision and Control, pp. 469-485, 2018. http:// doi.org/doi:10.1007/978-3-030-00253-4_20.

7. V. Kornienko, R. Radchenko, A. Stachel, A. Andreev, and M. Pyrysunko, "Correlations for pollution on condensing surfaces of exhaust gas boilers with waterfuel emulsion combustion," Advanced Manufacturing Processes. InterPartner-2019. Lecture Notes in Mechanical Engineering, Springer, Cham, pp. 530-539, 2020. Retrieved from http://doi:10.1007/978-3-030-40724-7_54.

8. Product manual scrubber (scrubber) (2013). Wartsila, 98 p. Retrieved from https://cdn.wartsila.com/docs/defaultsource/local-files/russia/products/project-guides/wärtsiläscrubber-product-guide-rev-c_rus.pdf?sfvrsn=73676f44_2.

9. Unit for reducing NOx emissions by technology SCR by WÄRTSILÄ. Retrieved from https://cdn.wartsila.com/docs/ default-source/local-files/russia/products/nox_reducersrus.pdf?sfvrsn=f1696f44_2.

10. O.V. Serazhutdinov and V.A. Chistyakov, "Technologies for the reduction of nitrogen oxides in the exhaust gases of marine diesel engines" Marine Intelligent Technology, №4-1(30), pp. 23-28, 2015.

11. V.V. Le and T.H. Truong, "A simulation study to assess the economic, energy and emissions characteristics of a marine engine equipped with exhaust gas recirculation," 1st International Conference on Sustainable Manufacturing,
Materials and Technologies, 2020. Retrieved from http:// doi.org/doi:10.1063/5.0000135.

12. R. Radchenko, M. Pyrysunko, V. Kornienko, R. Patyk, and O. Moskovko, "Improving the ecological and energy efficiency of internal combustion engines by ejector chiller using recirculation gas heat," ICTM 2020, Advances in Intelligent Systems and Computing, Springer, Cham, 10 p., 2020.

13. Y. Zhao, Y. Fan, K. Fagerholt, and J. Zhou, "Reducing sulfur and nitrogen emissions in shipping economically" Transportation Research Part D, Transport and Environment, vol. 90, 2021. Retrieved from https://doi.org/10.1016/j. $\operatorname{trd} .2020 .102641$.

14. New system PureSOx Express. Retrieved from https://www. alfalaval.ua/media/news/2020/new-alfa-laval-puresoxexpress-offers-easy-access-to-sox-scrubber-advantages/.

15. Y.-S. Choi, and T.-W. Lim, "Numerical simulation and validation in scrubber wash water discharge from ships," Journal of Marine Science and Engineering, vol. 8, no. 4, p. 272, 2020. Retrieved from http://doi.org/doi:10.3390/ jmse8040272.

16. S. Endres et al., "A new perspective at the ship-airsea-interface: The environmental impacts of exhaust gas scrubber discharge," Frontiers in Marine Science, vol. 5, 2018. Retrieved from http://doi.org/doi:10.3389/ fmars.2018.00139.

17. H. Xi, S. Zhou, and Z. Zhang, "A novel method using $\mathrm{Na}_{2} \mathrm{~S}_{2} \mathrm{O}_{8}$ as an oxidant to simultaneously absorb $\mathrm{SO}_{2}$ and NO from marine diesel engine exhaust gases," Energy \& Fuels, 2020. Retrieved from http://doi.org/doi:10.1021/acs. energyfuels.9b03334.

18. Y.A. Bystrov, S.A. Isayev, N.A. Kudryavtsev, and A. I. Leont'yev, Numerical Simulation of Heat Transfer Vortex Intensification in the Pipe Packs. St. Petersburg: Shipbuilding, 2005.

19. T.B. Gatski, M.Y. Hussaini, and J.L. Lumley, Simulation and Modelling of Turbulent Flows. Oxford, New York: Oxford University Press, 314 p., 1996. Retrieved from https://www.academia.edu/10100418/SIMULATION_ AND_MODELLING_OF_TURBULENT_FLOWS (last accessed: 20.01.2021).

20. S. Sarkar and L. Balakrishnan, Application of a ReynoldsStress Turbulence Model to the Compressible Shear Layer, 1990. Retrieved from https://apps.dtic.mil/dtic/tr/fulltext/ u2/a227097.pdf (last accessed: 20.01.2021).

21. Introducing code_Saturne. Retrieved from https://www. code-saturne.org/cms/. 
22. Computational Fluid Dynamics: CFD Software. Retrieved from https://www.simscale.com/product/cfd/.

23. B.V. Dymo, A.Y. Voloshyn, A.E. Yepifanov, and V.V. Kuznetsov, "Increase of ship power plants gas-air cooler efficiency," Problemele Energeticii Regionale, vol. 2, no. 34, pp. 113-124, 2017.

24. B.V. Dymo, A.Y. Voloshyn, and V.I. Kharchenko, "The research of gas-dynamic processes in the gas-air cooler of the ship power plant," Zbirnyk Naukovykh Prats' NUK, vol. 6, pp. 81-89, 2010.

25. A.A Khalatov, Heat Transfer and Fluid Mechanics over Surface Indentations (Dimples). Kiev: National Academy of Sciences of Ukraine, Institute of Engineering Thermophysics, 64 p., 2005.

26. V.V. Kuznetsov, "Generalization of the rules in the heat transfer of swirling flows inside the tubular channels of power plants heat transfer devices," Collection of Scientific Papers of Admiral Makarov National University of Shipbuilding vol. 5, pp. 46-52, 2015.

\section{CONTACT WITH THE AUTHORS}

\section{Valerii Kuznetsov}

e-mail:valeriy.kuznetsov@nuos.edu.ua Admiral Makarov National University of Shipbuilding, Heroyiv Ukraine av. 9, 54025 Mykolaiv,

\section{UKRAINE}

\section{Boris Dymo}

e-mail:dymobv@gmail.com

Admiral Makarov National University of Shipbuilding, Heroyiv Ukraine av. 9, 54025 Mykolaiv,

\section{UKRAINE}

\section{Svitlana Kuznetsova}

e-mail: svitlana.kuznetsova@nuos.edu.ua Admiral Makarov National University of Shipbuilding, Heroyiv Ukraine av. 9, 54025 Mykolaiv,

\section{UKRAINE}

\section{Mykola Bondarenko}

e-mail: bondarenko.nikola2308@gmail.com Admiral Makarov National University of Shipbuilding, Heroyiv Ukraine av. 9, 54025 Mykolaiv,

\section{UKRAINE}

\section{Andrii Voloshyn}

e-mail: voloshinandrey2011@gmail.com State Research Design \& Shipbuilding Centre, Heroyiv Ukraine av. 1E, 54025 Mykolaiv,

\section{UKRAINE}

